\title{
INFLUENCE OF CUSTOMER PRESSURE ON THE INNOVATIVE ACTIVITY OF A COMPANY
}

This article is based on the research conducted on the companies from five countries: Latvia, Lithuania, Russia, Estonia and Poland. These countries are all located in the southeastern part of the Baltic Sea. A review of the literature reveals no analysis of the intensity of customer impact on the innovative activity of a company. In this context, the main aim of the article is to analyse the influence and intensity of types of customer pressure on the innovative activity of a company. This article takes into account both the pressure from customers to introduce new products and the pressure from customers to lower the production costs. The research hypothesis allowing the attainment of the research goal is formulated as follows: The majority of innovations introduced by the companies from the countries of south-east part of the Baltic Sea are demand-driven, that is, they are a result of customer pressure. This means that the probability of occurrence of all the analysed attributes of innovative activity depends on the amount of pressure on the side of customers. With no pressure, the probability of occurrence of the analysed attributes of innovative activity is smallest.

Keywords: customer pressure, innovative activity, demand-driven innovation

DOI: $10.15611 /$ aoe.2015.2.11

\section{INTRODUCTION}

This article is based on the research conducted on companies from five countries: Latvia, Lithuania, Russia, Estonia and Poland. These countries are all located on the south-east of the Baltic Sea coast.

The notion of collaboration between a company and its customers has become an important element in the development process of many organisations. It has been a subject of many research papers. For example, between 2004 and 2006 a number of publications appeared, describing the influence of customer knowledge on the possibility of companies introducing new products (Franke, Piller, 2004, pp. 401-415; Franke, von Hippel, Schreier, 2006, pp. 301-315; Elofson, Robinson, 2007, 2567-2594). The impact of information coming from customers and suppliers on the innovative activity of companies has been researched by Prahalad and Ramaswamy (2000, pp. 79-87) and Skaggs and Youndt (2004, pp. 85-99),

\footnotetext{
* Departament of Innovation and Entrepreneurship, University of Zielona Góra
} 
among others. There are also publications related to the impact of customers on the innovative activity of companies from a given sector, for example: the manufacturers of sport shoes (Fuller, Jawecki, Muhlbacher, 2007, pp. 60-71), extreme sports equipment (Hienerth, 2006, pp. 273-294), medical equipment (Lettl, Herstatt, Gemuenden, 2006, pp. 251-272), video games (Jeppesen, Molin, 2003, pp. 363-383) and toys (Seybold, 2006).

The impact of customers on a company's innovative activity was also a subject dealt with by Schumpeter (1960, p. 369) and Chesbrough (2003, 2006, 2007, pp. 57-76), Lichtenthaler (2008, pp. 148-157) and Prandelli (Prandelli, Verona, Raccagni, 2006, pp. 109-135), when describing open innovations. The authors indicated that during the initial innovation phase, companies cannot handle the innovative activity on their own, without collaboration with other companies and consumers. Collaboration between producers or suppliers and customers is related to the increase in the number of products and services. Collaboration defined in such a manner is one of the main topics of interest in the area of open innovations, defined as a "systematic search performed by a company both inwards and outwards, storing and using knowledge in order to realise the innovative process" (Lichtenthaler, 2011, pp. 75-93). In general, open innovations seem to focus on the diffusion of knowledge "from" and "to" a company (Chesbrough, Crowther, 2006, pp. 229-236).

A review of the literature reveals no analysis of the intensity of customer impact on the innovative activity of a company. In this context, the main aim of the article is to analyse the influence and intensity of types of customer pressure on the innovative activity of a company. This article takes into account both the pressure from customers to introduce new products and the pressure from customers to lower the production costs. The research hypothesis allowing the realisation of the research goal is formulated as follows: the majority of innovations introduced by companies from the countries of the south-east part of the Baltic Sea coast are demand-driven, that is, these are a result of customer pressure. This means that the probability of occurrence of all the analysed attributes of innovative activity increases together with the amount of pressure on the part of customers. Whereas, with no pressure, the probability of the occurrence of the analysed attributes of innovative activity is at its lowest point. 


\section{LITERATURE REVIEW}

The relevant literature contains many criteria for categorising innovation. One of these is the categorisation of innovation in terms of continuity. From that point of view, innovation can be classified or divided as singular (sporadic) or systemic (Fabrizio, Thomas, 2011, p. 43). Singular innovations are those that only occur in a company from time to time. The reason behind their occurrence is, in most cases, the pressure from customers or competitors. Obtaining a new resource, the use of which increases the company's chances to be successful, is another cause for the occurrence of singular innovations.

Systemic innovations, in contrast, are found in companies with distinguished organisational units responsible for Research and Development (R\&D) activity. Such units have certain material and non-material resources at their disposal and utilise these to achieve innovation results that are only possible to implement in a production environment. What is most important is that, such units provide effects independently of the pressure from customers and competitors to introduce new products or to lower the production costs.

The above categorisation, into singular and systemic innovations, is closely related to the categorisation of innovation into demand-driven and supply-driven innovation. If a company realises its innovative activity only as a result of the pressure from clients, then in that company, demand-driven innovations are observed (von Hippel, 1988). Here, innovative activity is limited to reacting to the changing requirements of customers (Baran, Ostrowska, Pander, 2012, p. 27). For this reason, these are referred to as demand-driven innovations. Faced with increased demand, companies tend to invest more and develop their innovations as the result of market pressure (Schmookler, 1966; Newell, Jaffe, Stavins, 1999, pp. 941-975; Popp, 2002, pp. 160-180; Acemoglu, Linn, 2004, pp. 1049-1090). Striving to meet the ever increasing requirements, in turn, serves to improve the profitability of a company. One should keep in mind, however, that the demand levels and customer types vary greatly and in various ways influence the innovative activity of companies (Adner, Levinthal, 2001, pp. 611-628).

In contrast, if a company continues its innovative activities, despite the absence of pressure from customers and competitors, then what is known as supply-driven innovation takes place. This kind of innovation is alternatively described as technology-driven. This means that the knowledge stemming from basic sciences, applied sciences or design and production stimulates the 
innovative activity of a company (Dosi, 1982, pp. 147-162; Griliches, 1995, pp. 52-89; Nelson, 1982, pp. 453-470). The accumulation of knowledge resources and their systematic analysis by the company is the driving force behind the practical application of information related to the different branches of knowledge discovered by the company. One should keep in mind, however, that access to the accumulated knowledge - internal or external to a company - on its own is only a necessary condition for innovative activity to take place. In order to implement innovation, an idea is required regarding the use of the acquired knowledge for the benefit of the company.

The main problem faced by companies from these countries, formerly considered as developing countries, is the limited resources at their disposal (Świadek, Gorączkowska, 2013, p. 94). The lack of resources can result in these companies being unable to meet customer expectations, which typically leads to a deteriorating financial situation. The situation is even worse for the local companies, where the customers have the chance to compare their offer with that of companies from highly developed countries. This means that the companies from the less developed countries have to catch up with the changes in products offered in their home market by the companies from highly developed countries.

We emphasize the paradoxical situation where the weakness of the markets and companies from the less developed countries allow the local companies to keep operating. This is a result of the marketing strategies of the companies from highly developed countries: their newest products are offered in the first place to customers from highly developed countries, whereas the less developed countries observe the increased promotion of the older generation of products ${ }^{1}$. Owing to this marketing strategy, the companies from the less developed countries gain time for innovative activity and are able to introduce products that can be described as imitative innovations.

With such a marketing strategy and given the free flow of information, customer awareness in the developing countries has begun to gradually change. The customers are aware of the characteristics of products in the highly

\footnotetext{
${ }^{1}$ Microsoft Corporation is a good example; its newest Xbox console was available in 2013 in the following countries: Australia, Austria, Brazil, Canada, France, Germany, Ireland, Italy, Mexico, New Zealand, Spain, the United Kingdom and the USA. It is anticipated that it will be introduced to the countries like Estonia, Latvia, Lithuania, Poland and Russia with a year's delay but the customers from these countries can purchase the console now over the Internet from one of the international retailers.
} 
developed countries and demand that the local companies provide the products with similar characteristics. This, in turn, motivates the innovative activity of the local companies, striving to meet the demands of their customers.

\section{METHODOLOGICAL ASPECTS OF RESEARCH}

The empirical data on the basis of which we made our calculations and interpreted the results, were obtained during the fourth round of the business environment survey carried out between 2008 and 2009 for the European Bank for Reconstruction and Development (EBRD), and the World Bank. In total, 2609 companies from the south-eastern part of the Baltic Sea coast were the subject of the survey. Table 1 presents the structure of these companies, split into countries.

\section{Table 1}

The characteristics of the companies analyzed originating from the south-eastern part of the Baltic Sea coast

\begin{tabular}{l|c|c|c|c}
\hline \multirow{2}{*}{ Country } & \multicolumn{4}{|c}{ Number of companies } \\
\cline { 2 - 5 } & Total & $\begin{array}{c}\text { Processing } \\
\text { companies }\end{array}$ & $\begin{array}{c}\text { Retail } \\
\text { companies }\end{array}$ & $\begin{array}{c}\text { Other service } \\
\text { companies }\end{array}$ \\
\hline Estonia & 273 & 90 & 124 & 59 \\
\hline Latvia & 271 & 89 & 111 & 71 \\
\hline Lithuania & 276 & 97 & 113 & 66 \\
\hline Poland & 533 & 172 & 175 & 186 \\
\hline Russia & 1256 & 734 & 207 & 615 \\
\hline Total & 2609 & 1182 & 730 & 697 \\
\hline
\end{tabular}

Source: own analysis based on BEEPS 2009 data

There were three types of companies: processing, retail and other service that were included in the survey. An additional condition was that all the companies had to employ at least five full-time employees. As a result of these restrictions many kinds of state-run enterprises, including the army, police, health service and education were excluded. The survey covered companies from the following sectors (according to ISIC Rev. 3.1):

- Group D - companies involved in processing activities,

- Group F - companies involved in construction,

- Groups $\mathrm{G}$ and $\mathrm{H}$ - companies involved in services,

- Group I - companies involved in transportation, storage and communication. 
The survey did not cover the companies from Groups $\mathrm{J}$ and $\mathrm{K}$ (financial intermediation, real estate) with the sole exception of subsector 72: computer and related activities. Moreover, the survey did not include companies that are involved in farming and mining ${ }^{2}$.

The survey is of a static character and concerns the period 2006-2008, which is consistent with the methodological standards described in the Oslo Manual (2005). In order to reject or accept the research hypotheses, the following were defined as independent variables: a) pressure from customers to introduce new products, b) pressure from customers to lower the production $\operatorname{costs}^{3}$. The dependent variables were defined as the occurrence in a company of: a) product innovation, b) R\&D activity, c) process innovation, d) investments.

The above variables mirror the questions asked during the survey conducted for the EBRD and the World Bank. We note that the survey featured questions in a closed form, meaning that a list of possible answers was provided to choose from.

The chosen independent and dependent variables are dichotomous, meaning that they could be assigned either a value of 0 or 1 . In the case of variables describing innovative activity this means that either a company implemented a given innovative process (the variable was assigned 1) or it did not (in such cases the variable was assigned 0 ). The accepted dependent variables are dichotomous: taking the value of either 0 or 1 . In this particular case of dependent variables describing innovative activity, this means that the given type of innovative activity either occurred (with the variable taking the value of 1) or did not occur (with the variable taking the value of 0 ). In contrast, the independent variables are discrete, taking a value from the range between 0 and 3 , where 0 means "no pressure", 1 - "minimal pressure", 2 - "quite strong pressure" and 3 - "very strong pressure".

The dichotomous character of dependent variables means that the most popular modelling methods, such as multivariate regression, cannot be implemented. It is however possible to use logistic or probit modelling.

This article implements probit modelling, given the possibility of obtaining the probability value for a given attribute of innovative activity. These values tell us whether the probability of a given attribute is low (at the level of a few percent) or very high (e.g. $70-80 \%$ ). Note that in logit

\footnotetext{
2 A detailed description of survey methodology can be accessed at: http://www.enterprisesurveys.org/Methodology

${ }^{3} \mathrm{http}: / /$ www.enterprisesurveys.org/Methodology/ /media/FPDKM/EnterpriseSurveys/Docum ents/Methodology/Questionnaire-Manual.pdf
} 
modelling there is no such reference point. One obtains the odds ratio that carries information about the strength of association or non-independence between two data values.

The probit models yield the probability $p_{i}$ of the event $y_{i}=1$ depending on the independent variable, denoted $Z_{i}$. Interpreting this in the case of innovative activity one can say that the probit models output the probability of the occurrence of a given attribute of innovative activity in a situation of a specific pressure level.

The probit model assumes that the probability $p_{i}$ (referred to as probit) is described by a normal distribution function:

$$
p_{i}=F\left(Z_{i}\right)=\int_{-\infty}^{Z_{i}} \frac{1}{\sqrt{2 \pi}} \exp \left(-\frac{1}{2} t^{2}\right) d t
$$

where the independent variable (pressure) is treated as a linear combination of the variables describing the features that influence the occurrence of the following event:

$$
Z_{i}=\beta_{0}+\beta_{1} x_{1 i}+\beta_{2} x_{2 i}+\ldots+\beta_{k} x_{k i}+\varepsilon_{i} .
$$

The undeniable advantage of probit modelling is that the probability obtained falls between the values 0 and 1 . The probability of an event does not change linearly but increases or decreases ever slower, approaching 0 or 1 together with the changing values of $Z_{i}$. Hence, the interpretation of the parameters of probit models is not as obvious as in the case of linear models. Here, the partial derivative of $p_{i}$ with respect to for example $x_{k i}$ is defined as:

$$
\frac{\partial p_{i}}{\partial x_{k i}}=\beta_{k} \varphi\left(\beta_{0}+\beta_{1} x_{1 i}+\beta_{2} x_{2 i}+\ldots+\beta_{k} x_{k i}\right),
$$

where $\varphi(\cdot)$ is a probability density function of standardized Gaussian distribution.

The sign of the parameter $\beta_{k}$ determines the direction of influence of the $k$-th variable $x_{k i}$ on the probability of the occurrence of the analyzed event. The positive sign means that the probability of the dependent variable $y_{i}=1$ increases, whereas the negative sign means that the probability of the dependent variable $y_{i}=1$ decreases. Interpreting the above in terms of the analysis of innovative activity one can say that if $\beta_{k}$ has a positive sign, it means that the probability of the occurrence of a given attribute of innovative activity grows with the increase in customer pressure, whereas 
a negative sign means that the probability decreases with the increase in customer pressure.

This article presents calculations made using the STATISTICA suite. The models were estimated for the companies from all the countries separately as well as taking all the countries together. This meant the creation of six model groups, divided regionally. Within each of the groups, the models for four dependent variables (standing for the specified attributes of innovative activity of the companies) were calculated. As the analysis included two independent variables, eight probit models were created for the companies from each of the regional groups. In total, for all the countries of the southeast part of the Baltic coast, 48 probit models were created, out of which 24 were statistically significant and which are presented and discussed in the remainder of this article.

\section{THE IMPACT OF CUSTOMER PRESSURE INNOVATIVE ACTIVITY IN COMPANIES}

As mentioned, the innovative activity of companies is described using four attributes: product innovations, $\mathrm{R}+\mathrm{D}$, process innovations and financing innovative activity (investments).

\subsection{The impact of customer pressure on product innovations}

As a result of the analysis, nine statistically significant models were obtained relating to the impact of the variables: "customer pressure to introduce new products" and "customer pressure to lower the production costs" on the product innovations in the companies from the south-east part of the Baltic Sea coast. The obtained models are presented in the following table.

The models presented above imply that the increase in customer pressure means an increase in the innovative activity of companies in terms of product innovations. When a company feels no customer pressure or the pressure is minimal, the pressure to lower the production costs has a stronger impact on product innovations. Whereas, quite strong or very strong customer pressure means that the pressure to introduce new products is more important.

With no customer pressure or minimal pressure levels, the probability of product innovations in large and medium countries such as Russia and Poland is greater than the probability of product innovations in smaller 
Table 2

The models and probabilities describing the impact of the variables: "customer pressure to introduce new products" and "customer pressure to lower the production costs" on the product innovations

\begin{tabular}{|c|c|c|c|c|c|c|c|c|}
\hline \multirow{2}{*}{ Pressure type } & \multicolumn{4}{|c|}{$\begin{array}{l}\text { The intensity } \\
\text { of the pressure }\end{array}$} & \multirow{2}{*}{ SE } & \multirow{2}{*}{$\mathrm{Chi}^{2}$} & \multirow{2}{*}{$\mathbf{p}$} & \multirow{2}{*}{$\mathbf{L}$} \\
\hline & Lack & Min. & $\begin{array}{l}\text { Quite } \\
\text { strong }\end{array}$ & $\begin{array}{c}\text { Very } \\
\text { strong }\end{array}$ & & & & \\
\hline \multicolumn{9}{|c|}{ All countries examined together } \\
\hline \multirow{2}{*}{$\begin{array}{l}\text { Pressure from customer to } \\
\text { introduce new products }\end{array}$} & \multicolumn{4}{|c|}{$+0.11^{* * *} \mathrm{x}-0.20$} & \multirow{2}{*}{0.02} & \multirow{2}{*}{25.09} & \multirow{2}{*}{0.00} & \multirow{2}{*}{2544} \\
\hline & 0.47 & 0.51 & 0.56 & 0.60 & & & & \\
\hline \multirow{2}{*}{$\begin{array}{l}\text { Pressure from customers to } \\
\text { lower the production costs }\end{array}$} & \multicolumn{4}{|c|}{$+0.10^{* * * *} x-0.15$} & \multirow{2}{*}{0.02} & \multirow{2}{*}{18.02} & \multirow{2}{*}{0.00} & \multirow{2}{*}{2539} \\
\hline & 0.48 & 0.52 & 0.56 & 0.60 & & & & \\
\hline \multicolumn{9}{|c|}{ Russia } \\
\hline \multirow{2}{*}{$\begin{array}{l}\text { Pressure from customer to } \\
\text { introduce new products }\end{array}$} & \multicolumn{4}{|c|}{$+0.08^{* * *} \mathrm{x}-0.08$} & \multirow{2}{*}{0.03} & \multirow{2}{*}{5.83} & \multirow{2}{*}{0.02} & \multirow{2}{*}{1218} \\
\hline & 0.50 & 0.53 & 0.57 & 0.60 & & & & \\
\hline \multirow{2}{*}{$\begin{array}{l}\text { Pressure from customers to } \\
\text { lower the production costs }\end{array}$} & \multicolumn{4}{|c|}{$+0.08^{* * *} \mathrm{x}-0.08$} & \multirow{2}{*}{0.03} & \multirow{2}{*}{6.00} & \multirow{2}{*}{0.01} & \multirow{2}{*}{1226} \\
\hline & 0.50 & 0.53 & 0.57 & 0.60 & & & & \\
\hline & Po & and & & & & & & \\
\hline Pressure from customer to & & +0.1 & x-0.1 & & & & & \\
\hline introduce new products & 0.49 & 0.55 & 0.61 & 0.66 & 0.05 & 8.71 & 0.00 & 522 \\
\hline Pressure from customers to & & $+\mathbf{0 . 1}$ & $x-0.0$ & & 005 & 499 & 003 & 523 \\
\hline lower the production costs & 0.51 & 0.56 & 0.60 & 0.64 & 0.00 & 4.99 & 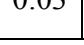 & 525 \\
\hline & Lith & uania & & & & & & \\
\hline Pressure from customer to & & +0.1 & $x-0.4$ & & 007 & 474 & 003 & 272 \\
\hline introduce new products & 0.37 & 0.43 & 0.49 & 0.55 & 0.01 & 4.14 & 0.03 & 212 \\
\hline & & tvia & & & & & & \\
\hline Pressure from customer to & & +0.2 & x-0.5 & & & & 01 & 263 \\
\hline introduce new products & 0.35 & 0.43 & 0.51 & 0.60 & 0.01 & 1.15 & 0.01 & 203 \\
\hline Pressure from customers to & & +0.1 & $x-0.5$ & & 008 & 550 & ? & 126 \\
\hline lower the production costs & 0.37 & 0.44 & 0.51 & 0.58 & 0.08 & 5.50 & 0.02 & 250 \\
\hline
\end{tabular}

where:

SE - standard error

$\mathrm{Chi}^{2}$ - Chi-square test,

$\mathrm{p}$ - statistical significancevalue,

${ }^{* * *}$ - parameter significance smaller than $0.99 \%$,

** - parameter significance from 1.00 to $1.99 \%$,

* - parameter significance from 2.00 to $4.99 \%$;

$\mathrm{L}$ - sample size.

Source: own analysis on the basis on the outcome of the fourth BEEPS round 
countries such as Lithuania or Latvia. On the other hand, in the case of a very strong pressure, the probability of product innovations is similar in all the analysed countries.

It is worth noting that in the case of small countries the probability scale related to the occurrence of product innovations with varying pressure levels is larger than an analogous probability scale in the case of medium and large countries. This is manifested by the fact that in the smaller countries, the difference in the probability of product innovations in the companies with no customer pressure and the companies with very strong customer pressure is in the $49-70 \%$ range, whereas in the case of large and medium countries this difference is observed in the $16-34 \%$ range. This means that, in the smaller countries, the increase in customer pressure has a greater impact on product innovations than in the case of medium and large companies.

\subsection{The impact of customer pressure on $R+D$}

Analyzing the impact of the independent variables "customer pressure to introduce new products" and "customer pressure to lower the production costs" on the $\mathrm{R}+\mathrm{D}$ activity in the companies, seven statistically significant models were obtained as presented in the following table.

Comparing the probabilities of $\mathrm{R}+\mathrm{D}$ and product innovations one clearly sees that the $\mathrm{R}+\mathrm{D}$ probability is decidedly lower. On the other hand, the general tendency for the probability of $\mathrm{R}+\mathrm{D}$ to increase with the increase of customer pressure is analogous to the case of product innovations. The lower values of $\mathrm{R}+\mathrm{D}$ probability means that a similar span (in absolute terms) between the extreme pressure values both in the case of $\mathrm{R}+\mathrm{D}$ activity and product innovations translates into a greater percentage increase for $\mathrm{R}+\mathrm{D}$ than in the case of product innovations. As a consequence, the extreme values of customer pressure growth caused the increase of $\mathrm{R}+\mathrm{D}$ probability from 52 to even $167 \%$.

Analysing the obtained results, it is important to notice that in the case of $\mathrm{R}+\mathrm{D}$ activity, there is no way of knowing exactly which of the pressure types has a stronger impact on $\mathrm{R}+\mathrm{D}$. For example, in Latvia with no or minimal customer pressure, the probability of $\mathrm{R}+\mathrm{D}$ activity has a greater value for pressure to introduce new products than for the pressure to lower the production costs, in Russia this relationship is reversed.

Note also that if with none or minimal pressure of one kind the probability of $\mathrm{R}+\mathrm{D}$ is higher, than with the same pressure but of quite strong or very strong intensity, the probability of $\mathrm{R}+\mathrm{D}$ is lower than in the case of the other type of pressure. 
Table 3

The models and probabilities describing the impact of the variables: "customer pressure to introduce new products" and "customer pressure to lower the production costs" on the $\mathrm{R}+\mathrm{D}$ activity in the companies

\begin{tabular}{|c|c|c|c|c|c|c|c|c|}
\hline \multirow[b]{2}{*}{ Pressure type } & \multicolumn{4}{|c|}{ The intensity of the pressure } & \multirow[b]{2}{*}{ SE } & \multirow[b]{2}{*}{$\mathrm{Chi}^{2}$} & \multirow[b]{2}{*}{$\mathrm{p}$} & \multirow[b]{2}{*}{$\mathrm{L}$} \\
\hline & Lack & Min. & $\begin{array}{l}\text { Quite } \\
\text { strong }\end{array}$ & $\begin{array}{l}\text { Very } \\
\text { strong }\end{array}$ & & & & \\
\hline \multicolumn{9}{|c|}{ All countries examined together } \\
\hline \multirow{2}{*}{$\begin{array}{l}\text { Pressure from customer to } \\
\text { introduce new products }\end{array}$} & \multicolumn{4}{|c|}{$+0.13 * * * x-0.95$} & \multirow{2}{*}{0.02} & \multirow{2}{*}{26.20} & \multirow{2}{*}{0.00} & \multirow{2}{*}{2544} \\
\hline & 0.20 & 0.24 & 0.28 & 0.33 & & & & \\
\hline \multirow{2}{*}{$\begin{array}{l}\text { Pressure from customers to } \\
\text { lower the production costs }\end{array}$} & \multicolumn{4}{|c|}{$+0.11 * * * x-0.92$} & \multirow{2}{*}{0.02} & \multirow{2}{*}{21.44} & \multirow{2}{*}{0.00} & \multirow{2}{*}{2539} \\
\hline & 0.21 & 0.25 & 0.28 & 0.32 & & & & \\
\hline \multicolumn{9}{|c|}{ Russia } \\
\hline \multirow{2}{*}{$\begin{array}{l}\text { Pressure from customer to } \\
\text { introduce new products }\end{array}$} & \multicolumn{4}{|c|}{$+0.16 * * * x-1.04$} & \multirow{2}{*}{0.04} & \multirow{2}{*}{20.65} & \multirow{2}{*}{0.00} & \multirow{2}{*}{1218} \\
\hline & 0.19 & 0.24 & 0.29 & 0.35 & & & & \\
\hline \multirow{2}{*}{$\begin{array}{l}\text { Pressure from customers to } \\
\text { lower the production costs }\end{array}$} & \multicolumn{4}{|c|}{$+0.14 * * * x-0.97$} & \multirow{2}{*}{0.04} & \multirow{2}{*}{15.05} & \multirow{2}{*}{0.00} & \multirow{2}{*}{1226} \\
\hline & 0.20 & 0.25 & 0.29 & 0.34 & & & & \\
\hline \multicolumn{9}{|c|}{ Estonia } \\
\hline \multirow{2}{*}{$\begin{array}{l}\text { Pressure from customers to } \\
\text { lower the production costs }\end{array}$} & \multicolumn{4}{|c|}{$+0.16 * x-0.96$} & & & & \\
\hline & 0.21 & 0.26 & 0.32 & 0.38 & 0.08 & 4.39 & 0.04 & 265 \\
\hline & & & itvia & & & & & \\
\hline Pressure from customer to & & $+\mathbf{0 . 1}$ & $* x-1.1$ & & 008 & 408 & 004 & 263 \\
\hline introduce new products & 0.15 & 0.19 & 0.24 & 0.29 & 0.08 & 4.08 & & 203 \\
\hline Pressure from customers to & & +0.2 & $x-1.3$ & & 0.09 & 687 & 0.01 & 256 \\
\hline lower the production costs & 0.12 & 0.18 & 0.24 & 0.32 & 0.09 & $6.8 /$ & 0.01 & 256 \\
\hline
\end{tabular}

Source: own analysis on the basis on the outcome of the fourth BEEPS round

Finally, in the case of customer pressure impact on $\mathrm{R}+\mathrm{D}$ activity, a country size does not influence the probability level of such an activity. The companies from Latvia (a small country) have a smaller probability of $\mathrm{R}+\mathrm{D}$ activity than in the case of the companies from Russia (an example of a large country). On the other hand, the $\mathrm{R}+\mathrm{D}$ probability in another small country, Estonia, is comparable to the probability of $\mathrm{R}+\mathrm{D}$ activity in the Russian companies.

\subsection{The impact of customer pressure on process innovations}

Regarding the impact of the variables: "customer pressure to introduce new products" and "customer pressure to lower the production costs" on process innovations implemented in a company, the smallest number (three) of statistically significant models were obtained. These are presented in Table 4. 
Table 4

The models and probabilities describing the impact of the variables: "customer pressure to introduce new products" and "customer pressure to lower the production costs" on implementing process innovations in the companies

\begin{tabular}{|c|c|c|c|c|c|c|c|c|}
\hline \multirow[b]{2}{*}{ Pressure type } & \multicolumn{4}{|c|}{ The intensity of the pressure } & \multirow[b]{2}{*}{ SE } & \multirow[b]{2}{*}{$\mathrm{Chi}^{2}$} & \multirow[b]{2}{*}{$\mathrm{p}$} & \multirow[b]{2}{*}{$\mathrm{L}$} \\
\hline & Lack & Min. & $\begin{array}{l}\text { Quite } \\
\text { strong }\end{array}$ & $\begin{array}{l}\text { Very } \\
\text { strong }\end{array}$ & & & & \\
\hline \multicolumn{9}{|c|}{ All countries examined together } \\
\hline \multirow{2}{*}{$\begin{array}{l}\text { Pressure from customer to } \\
\text { introduce new products }\end{array}$} & \multicolumn{4}{|c|}{$+0.09 x^{* * *+0.31}$} & \multirow{2}{*}{0.02} & \multirow{2}{*}{$\begin{array}{c}13.5 \\
6\end{array}$} & \multirow{2}{*}{0.00} & \multirow{2}{*}{2544} \\
\hline & 0.66 & 0.69 & 0.72 & 0.75 & & & & \\
\hline \multicolumn{9}{|c|}{ Russia } \\
\hline \multirow{2}{*}{$\begin{array}{l}\text { Pressure from customer to } \\
\text { introduce new products }\end{array}$} & \multicolumn{4}{|c|}{$+0.07 * x+0.41$} & \multirow{2}{*}{0.04} & \multirow{2}{*}{4.22} & \multirow{2}{*}{0.04} & \multirow{2}{*}{1218} \\
\hline & 0.24 & 0.26 & 0.29 & 0.31 & & & & \\
\hline \multicolumn{9}{|c|}{ Latvia } \\
\hline \multirow{2}{*}{$\begin{array}{l}\text { Pressure from customer to } \\
\text { introduce new products }\end{array}$} & \multicolumn{4}{|c|}{$+0.19 * * x-0.23$} & \multirow{2}{*}{0.07} & \multirow{2}{*}{6.48} & \multirow{2}{*}{0.01} & \multirow{2}{*}{263} \\
\hline & 0.48 & 0.56 & 0.63 & 0.70 & & & & \\
\hline
\end{tabular}

Source: own analysis on the basis on the outcome of the fourth BEEPS round

Analysing the obtained probit models one notices the lack of models describing the impact of customer pressure on lowering the production costs on process innovations in the companies. This means that this type of pressure does not impact process innovations. Whereas, in the case of customer pressure to introduce new products, the direction of dependence between the increase of pressure and probability of process innovations is the same as in the case of $\mathrm{R}+\mathrm{D}$ and product innovations. This means that the increase in pressure results in an increase in the probability of the occurrence of a given attribute of innovative activity.

In absolute term, the increase in customer pressure resulted in an increase of probability of process innovations in the range of $0.07-0.22(13-46 \%$ in terms of percentage). The case of Russia stands out in terms of the obtained probability values of process innovations, where the values were much lower than the average values calculated for all the analysed countries. This means that the customer pressure to introduce process innovations in Russia is markedly lower than in the rest of the countries. One can even say that in Russia, in the case of a very strong customer pressure, the probability of process innovations is lower than the probability of such innovations in the companies from the remaining countries where no customer pressure in that respect is observed. 


\subsection{The impact of customer pressure on financing innovative activity}

Financing innovative activity is the last analysed attribute of innovative activity. The following table presents the obtained probit models.

Table 5

The models and probabilities describing the impact of the variables: "customer pressure to introduce new products" and "customer pressure to lower the production costs" on financing innovative activity in the companies

\begin{tabular}{|c|c|c|c|c|c|c|c|c|}
\hline \multirow[b]{2}{*}{ Pressure type } & \multicolumn{4}{|c|}{ The intensity of the pressure } & \multirow[b]{2}{*}{$\mathrm{SE}$} & \multirow[b]{2}{*}{$\mathrm{Chi}^{2}$} & \multirow[b]{2}{*}{$\mathrm{p}$} & \multirow[b]{2}{*}{$\mathrm{L}$} \\
\hline & Lack & Min. & $\begin{array}{l}\text { Quite } \\
\text { strong }\end{array}$ & $\begin{array}{l}\text { Very } \\
\text { strong }\end{array}$ & & & & \\
\hline \multicolumn{9}{|c|}{ All countries examined together } \\
\hline \multirow{2}{*}{$\begin{array}{l}\text { Pressure from customer to } \\
\text { introduce New products }\end{array}$} & \multicolumn{4}{|c|}{$+0.05^{* *} x+0.13$} & \multirow{2}{*}{0.02} & \multirow{2}{*}{5.41} & \multirow{2}{*}{0.02} & \multirow{2}{*}{2544} \\
\hline & 0.57 & 0.59 & 0.61 & 0.64 & & & & \\
\hline \multirow{2}{*}{$\begin{array}{l}\text { Pressure from customers to } \\
\text { lower the production costs }\end{array}$} & \multicolumn{4}{|c|}{$+0.09^{* * * *} x+0.03$} & \multirow{2}{*}{0.02} & \multirow{2}{*}{16.68} & \multirow{2}{*}{0.00} & \multirow{2}{*}{2539} \\
\hline & 0.55 & 0.59 & 0.62 & 0.66 & & & & \\
\hline \multicolumn{9}{|c|}{ Lithuania } \\
\hline \multirow{2}{*}{$\begin{array}{l}\text { Pressure from customers to } \\
\text { lower the production costs }\end{array}$} & \multicolumn{4}{|c|}{$+0.15^{*} \mathrm{x}-0.22$} & \multirow{2}{*}{0.07} & \multirow{2}{*}{4.94} & \multirow{2}{*}{0.03} & \multirow{2}{*}{269} \\
\hline & 0.47 & 0.53 & 0.59 & 0.65 & & & & \\
\hline \multicolumn{9}{|c|}{ Estonia } \\
\hline \multirow{2}{*}{$\begin{array}{l}\text { Pressure from customer to } \\
\text { introduce New products }\end{array}$} & \multicolumn{4}{|c|}{$+0.17 x^{*}-0.24$} & \multirow{2}{*}{0.07} & \multirow{2}{*}{5.13} & \multirow{2}{*}{0.02} & \multirow{2}{*}{269} \\
\hline & 0.47 & 0.54 & 0.61 & 0.67 & & & & \\
\hline \multicolumn{9}{|c|}{ Latvia } \\
\hline \multirow{2}{*}{$\begin{array}{l}\text { Pressure from customers to } \\
\text { lower the production costs }\end{array}$} & \multicolumn{4}{|c|}{$+0.19^{* * *} \mathrm{x}-0.29$} & \multirow{2}{*}{0.08} & 605 & 001 & 256 \\
\hline & 0.46 & 0.54 & 0.61 & 0.68 & & & & 250 \\
\hline
\end{tabular}

Source: own analysis on the basis on the outcome of the fourth BEEPS round

The obtained models allow a comparison of financing innovative activity in the companies from smaller countries with the financing activity of all the analysed companies, including those from large and medium countries ${ }^{4}$. In the case of small-country companies, with no or minimal customer pressure, the probability of financing innovative activity is smaller than in the case of the companies from all the analysed countries. This regularity is observed both in the case of customer pressure to introduce new products and customer pressure to lower the production costs. Whereas, with a very strong pressure, the probability of financing innovative activity takes up values similar to the average values for all the analysed countries.

\footnotetext{
${ }^{4}$ It is important to notice that the companies from large and medium countries comprised as much as $68-69 \%$.
} 
It is also important to notice that in the case of small countries, the probability growth in extreme customer pressure values is greater than the probability growth calculated jointly for the companies from all the countries, that is predominantly for the medium and large companies. These growth values are greater both in absolute terms and when expressed as a percentage. This in turn means that the increase in customer pressure impacts stronger on the financing of investment activity in smaller countries than in all the countries taken together (that is: predominantly in the medium and large ones).

To summarize, the increased impact of customer pressure results in an increase in financing investment activity in the analysed companies.

\section{RESULTS}

An analysis of the obtained probit models confirms the hypothesis that the majority of innovations introduced by the companies from the countries of the south-east part of the Baltic Sea cost are demand-driven. This stems from the fact that the probability of all the analysed attributes grows together with the customer pressure, and where there is no customer pressure the probability of a given attribute of innovative activity is the smallest.

This relationship suggests that innovative activity in the analysed countries is not only demand-driven but also isolated. As a consequence, the most often observed innovations in the analysed countries are either the imitative or the corrective ones. The fact that innovations are demand-driven and isolated also explains why the pioneering innovations are so rare in the countries from the south-east part of the Baltic Sea coast.

Comparing the probability ranges for the distinguished attributes of innovative activity, the most homogeneous and at the same time the highest values were observed in the case of product innovations and investments. On the other hand, the probability of $\mathrm{R}+\mathrm{D}$ activity was in general the smallest. The probability of process innovations, however, varied the most. The process innovations probability was the lowest for Russian companies, comparable to the level of $\mathrm{R}+\mathrm{D}$ probability there. Note that the probability of process innovations for all the analysed countries together was similar to, or even slightly higher than, the probability of product innovations and investments.

Another conclusion drawn from the analysis is related to the impact the size of the country has on the probability of the occurrence of a given attribute of innovative activity. Among the large and medium countries 
(Russia and Poland) with no customer pressure, the probability of product innovations, $\mathrm{R}+\mathrm{D}$ and investments was higher than in the case of the small countries $^{5}$. On the other hand, with strong pressure levels, the size of the country was not as important. Russia - in terms of process innovations - was the only exception to this regularity: the probability values there were lower across all the customer pressure levels than in the case of Latvia and all the countries taken together.

The last conclusion relates to the probability range for the occurrence of particular attributes of innovative activity at the extreme values of customer pressure. The range of probability values in small countries across all attributes of innovative activity was larger than in the case of large and medium countries. This means that in smaller countries, such as Lithuania, Latvia and Estonia, the increase in customer pressure has a stronger influence on innovative activity of companies than in the case of medium and large countries.

\section{DISCUSSION}

The article forms a part of the research on the impact of customers on the innovative activity of companies. The arguments, verified by the empirical material, confirm the accuracy of the conclusions found in the literature concerning open innovations and customer impact on the innovative activity of companies. It is worth noting that the research described in the article is based on the data relating to the companies from the Baltic region. It is important to emphasize that the article uses the most up-to-date information available.

The conclusions emphasize the key role played by the pressure from customers in terms of the innovative activity of companies. The article differentiates between the customer impact on the demand-driven and supply-driven innovative activity. The conclusions only relate to the demand-driven innovation. The customer impact and pressure in relation to the supply-driven innovation requires separate verification.

The use of probit modelling to estimate the impact of various levels of pressure from customers on various levels of demand-driven innovative activity is the original contribution of the article in the research area.

\footnotetext{
${ }^{5}$ The probability of $\mathrm{R}+\mathrm{D}$ activity in Estonian companies was an exception, with values similar to those calculated for Russian companies.
} 


\section{REFERENCES}

Acemoglu, D., Linn, J., Market Size in Innovation: Theory and Evidence from the Pharmaceutical Industry, "Quarterly Journal of Economics”, No 119 (3), 2004.

Adner, R,, Levinthal, D., Demand Heterogeneity and Technological Evolution: Implications for Product and Process Innovation, "Management Science" No 47 (5), 2001.

Baran, M., Ostrowska, A., Pander, W., Demand-driven Innovations or How Innovations Are Created Today, PARP, Warszawa, 2012.

Chesbrough, H. W., Open Innovation: The New Imperative for Creating and Profiting from Technology. Harvard Business School Press, Boston, MA, 2003.

Chesbrough, H. W., Open Business Models: How to Thrive in the New Innovation Landscape. Harvard Business School Press, Boston, MA, 2006.

Chesbrough, H., Crowther, A. K., Beyond High Tech: Early Adopters of Open Innovation in Other Industries, "R\&D Management", Vol. 36, 2006.

Chesbrough, H., Appleyard, M. M., Open Innovation and Strategy, "California Management Review", Vol. 50, 2007.

Dosi, G., Technological Paradigms and Technological Trajectories, "Research Policy", Vol. 11(3), 1982.

Economics of Innovation and Technological Change, Stoneman P (ed). Blackwell: Oxford, UK.

Elofson, G., Robinson, W. N., Collective Customer Collaboration Impacts on Supply-chain Performance, "International Journal of Production Research", 45, 2007.

Fabrizio, K. R, Thomas, L. G., The Impact of Local Demand on Innovation in a Global Industry, "Strategic Management Journal", Vol. 33.

Franke, N., Piller, F., Value Creation by Toolkits for User Innovation and Design: The Case of the Watch Market, "Journal of Product Innovation Management", Vol. 21, 2004.

Franke, N., von Hippel, E., Schreier, M., Finding Commercially Attractive User Innovations: A Test of Lead-User Theory, "Journal of Product Innovation Management", Vol. 23, 2006.

Fuller, J., Jawecki, G., Muhlbacher, H., Innovation Creation by Online Basketball Communities, "Journal of Business Research", Vol. 60, 2007.

Griliches, Z., 1995, R\&D and productivity: econometric results and measurement issues, In Handbook of the

Hienerth, C., The Commercialization of User Innovations: The Development of the Rodeo Kayak Industry, "R\&D Management", Vol. 36, 2006.

IMF Emerging and Developing Economies List. World Economic Outlook Database

Jeppesen, L. B., Molin, M. J., Consumers as Co-developers: Learning and Innovation Outside the Firm, "Technology Analysis and Strategic Management", Vol. 15, 2003.

Lettl, C., Herstatt, C., Gemuenden, H. G., Users' Contributions to Radical Innovation: Evidence from Four Cases in the Field of Medical Equipment Technology, "R\&D Management", Vol. 36, 2006.

Lichtenthaler, U., Open Innovation in Practice: An Analysis of Strategic Approaches to Technology Transactions, "IEEE Transactions of Engineering Management", Vol. 55, 2008.

Lichtenthaler, U., Open Innovation: Past Research, Current Debates, And Future Directions, "Academy of Management Perspectives", Vol. 25, 2011. 
Nelson, R. R., The Role of Knowledge in R\&D Efficiency, "Quarterly Journal of Economics" No 97(3), 1982.

Newell, R. G, Jaffe, A. B., Stavins, R. N., The Induced Innovation Hypothesis and Energysaving Technological Change, "Quarterly Journal of Economics" No 114 (3), 1999.

Oslo Manual. Guidelines for Collecting and Interpreting Innovation Data. $3^{\text {rd }}$ Edition, 2005.

Popp, D., Induced Innovation and Energy Prices, "American Economic Review” No 92 (1), 2002.

Prahalad, C. K., Ramaswamy, V., Co-opting Customer Competence, "Harvard Business Review", Vol. 78, 2000.

Prandelli, E., Verona, G., Raccagni, D., Diffusion of Web-based Product Innovation, "California Management Review", Vol. 48, 2006.

Schmookler, J., 1966, Invention and Economic Growth Development. Harvard University Press, Cambridge, MA, 1966.

Schumpete J., Teoria Rozwoju Gospodarczego. PWN, Warszawa, 1960.

Seybold, P. B., Outside Innovation: How Your Customers Will Co-Design Your Company's Future. Harper Collins, New York, 2006.

Skaggs, B. C., Youndt, M., Strategic Positioning, Human Capital, and Performance in Service Organizations: A Customer Interaction Approach, "Strategic Management Journal", Vol. 25, 2004.

Sullivan, A., Economics: Principles in Action. Pearson Prentice Hall, 2003.

Świadek, A., Gorączkowska, J., Sources, Limitations and Results of Innovative Activity in the Lubuskie (2009-2011) - Probit Modelling, "Oeconomia Copernicana", No 1, 2013.

von Hippel, E., The Sources of Innovation. Oxford University Press, Oxford, UK, 1988. www.enterprisesurveys.org/Methodology

Received: April 2014, revised: May 2015 